Revista Complutense de Educación

ISSNe: 1988-2793

http://dx.doi.org/10.5209/RCED.61771

\title{
Educación y Desarrollo Humano
}

Autor: Fernando Gil Cantero, (ed.)

Editorial: Revista Española de Pedagogía

Año de publicación: 2017

$N^{o}$ de páginas: 111

ISBN: 978-84-16602-67-4

Este es un libro editado por la Revista Española de Pedagogía en 2017 que agrupa un conjunto de artículos publicados en los últimos años sobre el tema concreto que trata su título, Educación y Desarrollo Humano.

Como el profesor Gil Cantero expone en su Prólogo, entre las muchas discusiones interesantes pocas de ellas alcanzan a tratar las bases antropológicas de la cuestión educativa en cada caso.

Para ello basta dirigir la atención a las justificaciones necesarias que orienten al sentido humano capaz de perfeccionar la acción.

El libro objetiva diversas cuestiones básicas de la educación y del desarrollo humano publicadas en los últimos años en la Revista. Los autores en general están en un proceso de demostrar todavía sus habilidades pedagógicas y de aportar sus conocimientos adquiridos o en reflexión.

El profesor Ignacio Delgado González, de la Universidad de Salamanca, en su artículo seleccionado, plantea con claridad la necesidad de una fundamentación antropológica integral del hombre como ser personal, dialógico, libre y trascendente que nos permita acceder a la comprensión completa de la realidad educativa. Su enfoque es clásico y recurre a las aportaciones de autores como Buber, Levinas y Munier y su filosofía dialógica y personalista buscando la unidad total del ser humano en sus dimensiones natural, cultural y personal. Todo en el hombre apunta a la educación y culmina en ella según el autor, otorgándole a la vida su verdadero sentido. La escuela de hoy debería centrarse en la formación de personas libres y comprometidas con los valores que elevan la dignidad de la existencia.

El segundo artículo incluido en esta colección es del profesor Juan Luis Lorda, de la Universidad de Navarra, en el que presenta evidencias lógicas sobre el desarrollo de la persona, muestra la amplitud del sentido orientador al reconocer al educando como sujeto y no como objeto de la educación. Para el autor la educación es un milagro que se consigue no solo enseñando sino aprendiendo y comprendiendo con sano realismo que la educación se consigue imperfectamente con la acumulación de muchas acciones imperfectas. La educación es una de las artes más nobles de la vida humana porque trabaja con lo más noble que hay sobre la tierra: las personas. El arte de educar es la capacidad del docente de despertar las potencialidades latentes del educando para que éste pueda apreciar los bienes invisibles y poner orden en su sistema de preferencias. Las áreas que deben cultivarse en el arte educativo son la verdad, la bondad y la belleza. 
El profesor Jesús A. Beltrán Llera -fallecido en 2014- de la Universidad Complutense centra su contribución en la educación como sujeto del cambio administrativo, institucional, social, cultural y científico; y en la educación como agente activo del cambio de las personas. Los ejes fundamentales para el profesor Beltrán del cambio educativo son: Enseñanza de calidad para todos, Respeto a la diversidad, Cambiar obstáculos de actitudes y conductas discriminatorias, y Autonomía responsable de los estudiantes. El autor se pregunta si la educación debe cambiar, y cómo, para adaptarse a las exigencias de una sociedad en cambio o si debe permanecer inalterable en sus principios a través del tiempo. También, si la educación es capaz de cambiar la conducta y el rendimiento de los estudiantes. En sus páginas trata de dar respuesta a estas preguntas.

Christoph Wulf, profesor de la Universidad Libre de Berlín, desarrolla la idea de que el aprendizaje es multimodal (aprender a conocer, aprender a hacer, aprender a vivir con los demás, y aprender a ser), reconociendo la importancia de lo mimético, performativo y poiético para conseguir efectos personales duraderos concretamente en la Educación para la paz, la Educación en la diversidad cultural y el Desarrollo sostenible. La supervivencia de la humanidad consiste en el análisis y reducción de la violencia ejercida sobre la naturaleza y las generaciones futuras a través del consumo de recursos no renovables.

La profesora Raquel Ayala Carabajo analiza la experiencia cotidiana de la esperanza por parte de los educadores en sus relaciones educativas con los educandos, especialmente desde la perspectiva de la experiencia vivida. Su metodología fenomenológica-hermenéutica se basa en la formulada por Max van Manen, métodos descriptivos e interpretativos que descubren un conjunto de significados o estructuras esenciales del fenómeno de la esperanza pedagógica.

Finalmente, el desarrollo humano en el contexto difícil de las prisiones constituye el tema tratado por el profesor Fernando Gil Cantero, de la Universidad Complutense, abriendo paso a la idea de que no debemos dejar fuera de las posibilidades educativas de cambio personal a nadie que quiera volver a tener una segunda oportunidad.

El libro consigue así unir en un solo volumen, disponible en internet, un conjunto de contribuciones relacionadas en el tema tratado por diversos autores que contribuyeron con sus trabajos en la Revista Española de Pedagogía en los últimos años, del mismo modo que otras revistas internacionales hacen periódicamente ofreciendo a los lectores interesados ejemplos de sus artículos, en este caso relacionados con el desarrollo humano y la educación.

La reflexión que creo que puede hacerse es que la educación debe cuidar lo más valioso que encontramos en la tierra, la persona humana, y hacer que su desarrollo sea un recorrido de buenos consejos, amor, y admiración y aprecio por lo que existe, respetando lo recibido, que miremos advertidamente las posibles consecuencias de los comportamientos inapropiados personales, sociales y del medio ambiente, y que seriamente contribuyamos a un uso previsor y precavido de todo el entorno con criterios de verdad, vida digna y perdurabilidad tanto a nivel material como espiritual. La aportación cristiana da respuesta válida y convincente a todas las aspiraciones más profundas del corazón humano y a su pleno desarrollo, y una razón que no se autolimite a priori, por ejemplo reduciendo el conocimiento posible, no la contradice. 